\title{
Dewey e os sofistas: a tirania do lógos e as bases para uma educação retórica ${ }^{1}$
}

\author{
Dewey and the sophists: the tyranny of logos and the bases for a rhetorical education
}

Tatiane da Silva*

\section{Resumo}

A comparação dos princípios filosóficos e educacionais de John Dewey com as teses de filósofos que escreveram na Grécia Clássica constitui um recurso frutífero para compreender as concepções e propostas deweyanas. O presente trabalho analisa as concepções Sofísticas, especialmente as de Protágoras, Górgias e Hípias, juntamente com teorizações de Dewey, focalizando a relevância do lógos, entendido como comunicação, raciocínio, inteligência e deliberação em uma sociedade democrática, evidenciando a demanda por uma educação retórica. A metodologia utilizada para elaborar os marcos discursivos dos autores analisados é a análise retórica, cujo fundamento são as proposições aristotélicas retomadas por Chaïm Perelman e Lucie Olbrechts-Tyteca (1996). A argumentação dos Sofistas e a de Dewey evidenciam que o desenvolvimento do homem e da inteligência humana se dá por meio do método experimental, quando os indivíduos se envolvem nas discussões a respeito da homonoia, dos consensos, que direcionam a vida da sociedade. Mediada pelos métodos democráticos de persuasão, raciocínio, comunicação, deliberação e debate, a participação viabiliza experiências mais amplas, ricas, emancipadoras e compartilhadas. O alcance e a concretização da participação dependem do acesso dos indivíduos a uma educação retórica que os habilite a examinar e julgar as diversas opiniões que se apresentam e criar novas perspectivas de ação.

Palavras-chave: Democracia. Educação. John Dewey. Retórica. Sofistas.

\section{Abstract}

The comparison of John Dewey's philosophical and educational principles with the theses of philosophers who wrote in Classical Greece is a fruitful resource for understanding his conceptions and proposals. The present work analyzes the Sophistic conceptions, especially those of Protágoras, Górgias and Hípias, together with Dewey's theorizations, focusing on the relevance of the logos, understood as communication, reasoning, intelligence and deliberation in a democratic society, which suppose the demand for a rhetorical education. The methodology used to elaborate the discursive frameworks of the analyzed authors is the rhetorical analysis, whose foundation are the Aristotelian propositions taken up by Chaïm Perelman and Lucie Olbrechts-Tyteca (1996). The arguments of the Sophists and Dewey show that the development of man and human intelligence occurs through the experimental method, when individuals engage in discussions about the homonoia, the consensus, which direct the life of society. Mediated by democratic methods of persuasion, reasoning, communication, deliberation and debate, participation enables broader, richer, emancipatory and shared experiences. The scope and achievement of participation depends on the access of individuals to a rhetorical education that enables them to examine and judge the diverse opinions that are presented and to create new prospects for action.

Keywords: Democracy. Education. John Dewey. Rhetoric. Sophists.

\author{
Recebido em 30/06/2017 - Aprovado em 27/11/2017 \\ http://dx.doi.org/10.5335/rep.v25i1.8035
}

\footnotetext{
Doutora em Educação Escolar pela Universidade Estadual Paulista Júlio de Mesquita Filho (Unesp). E-mail: tathisilvausp@gmail.com
} 


\section{Introdução}

Comparar as teses de John Dewey com filosofias elaboradas em momentos pretéritos da história não é uma abordagem pioneira, pois tem sido posta em prática por diversos pesquisadores interessados em compreender os posicionamentos filosóficos e educacionais deweyanos no interior das problemáticas da Era Contemporânea. Joseph Chambliss (1990) e Jim Garrison (2006), por exemplo, tratam das relações entre Dewey e Aristóteles, e Stephen Toulmin (2008) sugere haver semelhanças entre Dewey e Pirro de Élis. Entretanto, o que buscamos, neste trabalho, é oferecer elementos para uma discussão recente: a análise das relações entre o pensamento deweyano e as concepções Sofísticas.

Por muito tempo, os historiadores da filosofia consideraram erroneamente os Sofistas como um grupo homogêneo e adotaram as informações e os juízos de valor de Platão e Aristóteles sobre eles, o que ocasionou a desvalorização dessa corrente filosófica, vista por muitos como responsável pela grave decadência do pensamento grego. Somente no século XX, tornou-se possível realizar a revisão sistemática dos juízos até então emitidos, propiciando a "radical reavaliação histórica" que conduziu à conclusão de que os Sofistas representaram um "elo essencial na história do pensamento antigo" (REALE; ANTISERI, 2007, p. 73). Tal reavaliação pode ser vista na obra de George Briscoe Kerferd (2003), O movimento sofista; no trabalho de Bárbara Cassin (1990), Ensaios sofísticos; e no livro de John Poulakos (1995), Sophistical rhetoric in Classical Greece.

Dentre as obras que tomam os Sofistas como objeto de análise, temos o estudo de Nathan Crick (2010), intitulado Democracy and rhetoric. Esse autor participa do movimento contemporâneo de revitalização dos Sofistas, sendo também um estudioso das ideias de John Dewey. De acordo com Crick, a tradição humanista iniciada na Grécia Antiga pela Sofística pode ser notada nas obras desse filósofo americano contemporâneo em razão de sua profunda "crença no potencial emancipatório da experiência estética" (2010, p. 4). Para os gregos, arte era techné, termo relativo a "todos os ramos de habilidade humana ou divina, ou inteligência aplicada, em oposição ao trabalho sem ajuda da natureza" (2010, p. 4-5). Tal afirmação pode ser ratificada na obra Experience and nature, na qual Dewey considera que os Sofistas ensinaram que o homem pode controlar amplamente as fortunas da vida pelo domínio das artes, por meio das artes instrumentais, "artes do controle baseadas no estudo da natureza, objetos que eram gratificantes e bons podem ser multiplicados" (1925/2008, p. 105).

A influência dos Sofistas nas reflexões deweyanas é ressaltada por Crick, tomando por base uma passagem de Democracia e educação, na qual Dewey afirma 
que os Sofistas foram "o primeiro corpo de educadores profissionais na Europa", tendo empregado o "método experimental da educação" não em causa própria, mas como uma técnica adequada para cultivar uma "cidadania crítica, competente e participativa necessária à sustentação da democracia” (1916/1959, p. 330 apud 2004, p. 177). Para Crick (2004, p. 178), os Sofistas mostraram a Dewey, por meio de seu método experimental educacional, que não nos tornamos democráticos primeiro para depois nos tornamos mais inteligentes, mas que nos tornamos mais inteligentes por aprender a atuar democraticamente.

Segundo Crick, as menções feitas por Dewey aos Sofistas revelam que o filósofo americano situava todos os discursos e artes no interior de uma "complexa rede de forças sociais" (2010, p. 6). Dewey enaltece a comunicação como meio "indispensável para alargar e enriquecer práticas de liberdade" que eram cultivadas desde os primórdios pela civilização grega $(2010$, p. 6). Seu alinhamento à arte retórica, postulado por Crick, permite caracterizar a filosofia deweyana como constituída por uma "latente atitude sofística" que "valoriza a individualidade radical, a experiência estética, a inteligência criativa e a persuasão" como "meios produtivos para a formação de comunidades de juízos" (2010, p. 10).

Vale ressaltar que o caráter global da filosofia de Dewey está mais próximo das formulações aristotélicas do que da Sofística; no entanto, os Sofistas representam algo que não se encontra em Aristóteles: "uma atitude consistente com os movimentos contemporâneos da pedagogia democrática" (SCHIAPPA, 2003, p. 178). Sendo assim, aproximar Dewey dos Sofistas e colocar suas ideias para pensarmos a educação brasileira, entendendo as particularidades de nosso meio, provêm o que, nas palavras de Schiappa, constitui uma "valiosa alternativa" às "tradições pedagógicas platônica e aristotélica", as quais permeiam muitos debates e práticas educacionais da atualidade (1994, p. 67).

Tomando por base essa breve exposição, o objetivo deste trabalho consiste em comparar as concepções Sofísticas, especialmente as de Protágoras, Górgias e Hípias, com as de Dewey, no que tange ao poder e à importância do lógos, entendido como comunicação, raciocínio, inteligência e deliberação em uma sociedade democrática, evidenciando que essa associação demanda uma educação retórica para os indivíduos. Para a consecução de nosso objetivo, analisaremos as seguintes obras de Dewey: Democracia e educação (1916/1959a), Reconstrução em filosofia (1920/1959b), Human nature and conduct (1922/2003), Experience and nature (1925/2008). Para a análise das argumentações dos Sofistas, iremos recorrer ao Elogio de Helena, obra de Górgias; a frase do homem-medida de Protágoras; e, de Platão, daremos especial ênfase aos diálogos Protágoras (PLATÃO, 2007), Hípias Maior (PLATÃO, 2016) e Teeteto (PLATÃO, 1997). 
Para o estudo desses textos, utilizaremos a metodologia denominada análise retórica, com a qual buscaremos elaborar os marcos discursivos dos autores analisados em consonância com os trabalhos do grupo de pesquisa Retórica e Argumentação na Pedagogia (USP/CNPq), cujo fundamento compreende as proposições aristotélicas retomadas por Chaïm Perelman e Lucie Olbrechts-Tyteca (1996). Consideramos marcos discursivos determinadas "formas típicas de elaborar e solucionar problemas filosóficos" expressos em "formas argumentativas peculiares" (SILVA, 2013, p. 23). A identificação e a análise desses marcos por meio da metodologia retórica permitem visualizar elementos comuns no discurso de autores com certa proximidade de pensamento, revelando núcleos argumentativos similares, mesmo que suas proposições estejam separadas por vários séculos e situadas em diferentes contextos. Com a localização de marcos discursivos, podemos refletir sobre a função dessas formas típicas de argumentar na constituição das propostas educacionais peculiares presentes em autores que compartilham certos núcleos argumentativos.

\section{A Sofística e a tirania do lógos}

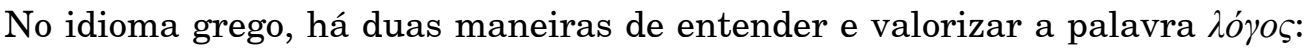
a primeira como Lógos, como pensamento adequado a uma Verdade absoluta; a segunda, como lógos, como discurso que faz emergir o sentido, o consenso, a verdade provisória e instável, base sobre a qual se estabelecem as relações humanas (VALLE, 2008, p. 512). ${ }^{2}$

A forma Lógos opera sob o respaldo de uma physis, ou seja, de uma ordem transcendente e imutável que independe dos homens, impondo aos indivíduos e ao mundo em que habitam um discurso que deve se adequar à Realidade superior e perfeita, o mundo da ordem, palco do conhecimento verdadeiro, do pensamento racional e da imutabilidade. A manifestação mais significativa do poder do Lógos, reflexo das elaborações de Parmênides, se deu por intermédio de Platão, em uma de suas narrativas míticas, o Mito dos Metais, ao afirmar que todos os indivíduos pertencentes à sua sociedade modelo são "irmãos", mas que o deus que os moldou "misturou um pouco de ouro" naqueles que estão "aptos a governar", sendo esse o motivo de serem eles "mais preciosos" (PLATÃO, 2006).

O consenso que se busca sobre cada assunto, tanto no âmbito da pólis quanto na esfera da vida privada, é uma homonoia, ${ }^{3}$ uma identidade de pensamento, resultante do acordo firmado entre poucos homens - os melhores, naturalmente capazes de conhecer e refletir sobre a realidade superior e, assim, decidir o destino de todos. A característica autoritária e impositiva do Lógos mostra aos membros 
da sociedade grega que nem todos possuem os elementos inatos necessários para se posicionar acerca dos negócios da pólis. Sendo assim, cada indivíduo deve se conformar com seu lugar na sociedade e aceitar a direção dos melhores, uma vez que as condições naturais para conduzir o grupo não se distribuem igualmente.

Por intermédio de seus questionamentos e discursos, os Sofistas expuseram a arbitrariedade e a vulnerabilidade dos legados da tradição e da ontologia parmenidiana. ${ }^{4}$ Sua atuação liberou o lógos das amarras do Ser imutável, fundamentando-o na fluidez das relações humanas e do tempo, tendo por característica o contingente, o plausível, o provisório, o que está sujeito a mudanças constantes, o raciocínio, o debate, a comunicação e a deliberação. A manifestação mais marcante do tirano lógos se deu por intermédio do estadista Péricles, em sua Oração fúnebre. Esse lógos difere do tirano Lógos, que eleva alguns homens a um patamar superior ao dos demais na pólis ideal de Platão. O lógos veiculado por intermédio de Péricles afirma que a sociedade grega, especialmente a democracia ateniense, depende não de poucos, mas da maioria (TUCÍDIDES, II, 60): cada cidadão ateniense deve decidir a respeito das questões de natureza pública, uma vez que "não é o debate que é empecilho à ação, e sim o fato de não se estar esclarecido pelo debate antes de chegar a hora da ação" (TUCÍDIDES, II, 40), diz o estadista.

A tirania do lógos, diferindo da que é exercida por seu homônimo, não tem por objetivo "impor seus pensamentos e seus desejos" sobre os indivíduos no mundo concreto. Enquanto os tiranos tradicionais sobrevivem por restringirem ao máximo a esfera de liberdade na ação e no discurso, o tirano lógos força os cidadãos à liberdade, arrancando-os de suas casas para falarem e serem falados no palco das assembleias, na corte e na ágora. Para essa tirania, cada indivíduo que compõe a sociedade tem algo a oferecer ao debate sobre os assuntos que concernem ao destino de todos na pólis. Perde fundamento a ideia de capacidade natural, que amparava o império da vontade dos melhores e de uma Realidade superior; no terreno do contingente, não há certezas absolutas, tudo deve ser periodicamente debatido por todos, a pluralidade de opiniões se faz presente, e as diferenças entre os indivíduos devem ser resolvidas por meio do diálogo em busca do consenso, para que a ação se efetue.

A homonoia Sofística é essencialmente um consenso retórico que busca a contínua criação da cidade pelo lógos. Um consenso do tipo Sofístico é sempre o que resulta de uma "operação retórica de persuasão", cuja tarefa é produzir, ocasião após ocasião (kairós), uma "unidade instantânea inteiramente feita de diferenças" (CASSIN, 1990, p. 76). Com a destituição da identidade ontológica e com a afirmação da prática retórica permitida pelos debates na democracia, vemos então a construção de uma identidade que leva em consideração a diversidade de opiniões 
(CASSIN, 1990, p. 13). As opiniões constituintes dessa identidade podem ter as suas singularidades harmonizadas por intermédio do debate e da deliberação conjunta ou, então, ser transformadas para produzir uma opinião comum inteiramente nova (CASSIN, 1990, p. 143).

Nesse novo contexto, o poder da palavra torna-se o objeto principal dos ensinamentos Sofistas, que acreditavam que, por intermédio da formação no lógos, os homens podem atingir formas mais elevadas de associação humana. Naquele ambiente renovado, a democracia é assumida como o espaço ideal para levar a cabo essa formação. Como veremos a seguir, a fé professada pelos Sofistas, tal como a fé professada mais tarde por Dewey, não era depositada na esperança de que alguma força maior viesse salvar os homens do mundo errante em que viviam; tratava-se, isto sim, de uma fé no "poder libertador do espírito humano", um poder desencadeado pelas formas coletivas de comunicação democrática, incluindo a que chamamos de retórica (CRICK, 2010, p. 186).

\section{Os Sofistas e o poder do lógos na formação do cidadão democrático}

Para entendermos a importância do lógos e da participação política na formação dos indivíduos segundo as concepções de Protágoras, devemos examinar a ideia central de sua doutrina do homem-medida, bem como a sua narrativa do Mito de Prometeu, conforme o retratado por Platão no diálogo que leva seu nome.

A afirmação protagoreana de que o homem é a "medida de todas as coisas" deslocou todo o peso das investigações filosóficas para as relações humanas que se efetivam no mundo concreto. Ao negar toda a realidade transcendental e eliminar aquela agradável segurança fornecida pelo mundo imutável, o filósofo de Abdera não abandonou os homens a um "caos relativista"; ele simplesmente abandonou a ordem do mundo impessoal do tirano Lógos, dando preferência à ordem contingente e humanista do tirano lógos, representante da atividade humana contínua e cumulativa de impor significado às aparências por meio da linguagem (CRICK, 2015a, p. 64).

Partindo dessas considerações, temos que, na concepção protagoreana, cabe ao homem o peso da responsabilidade por julgar fenômenos, ideias, valores, normas e conhecimentos no mundo concreto. Ao formular a sua famosa frase, Protágoras tinha em mente a noção de homem como ser individual e, ao mesmo tempo, membro de uma comunidade. Entretanto, só entendemos toda a importância do lógos e da política na formação dos homens como seres particulares e coletivos quando analisamos dois aspectos do Mito de Prometeu. 
Protágoras deixa-nos saber que, após receberem de Prometeu o fogo e as artes, os seres humanos tornaram-se o único animal a venerar os deuses e a articular a voz e as palavras. Mas, nem por isso tornaram-se senhores da arte política, pois passaram a viver esparsos e isolados (Protágoras, 322); ou, então, matando uns aos outros e cometendo injustiças. Zeus, então, envia Hermes para dar a todos os homens aidos (pudor, bom comportamento, moderação, percepção ou domínio de si) e dike (justiça) (Protágoras, 322d).

O primeiro aspecto a ser ressaltado é que Protágoras deixa bem claro que articular palavras e voz não traz ao homem a possibilidade de viver em harmonia com os outros, muito menos desenvolve neles a virtude política ou cívica. Essa virtude foi desenvolvida somente após a obtenção dos elementos fornecidos por Zeus, os quais possibilitaram que todos tomassem posição nas deliberações e nos debates políticos da sociedade. O primeiro passo na formação do homem como ser social foi dado quando os homens passaram a fazer mais do que articular sons e voz, aprendendo a discursar e discutir os problemas da comunidade à qual pertencem, desenvolvendo o lógos como comunicação, raciocínio, deliberação.

Outro ponto crucial para entendermos a visão de Protágoras diz respeito ao fato de que aidos e dike, diferentemente das artes e das técnicas fornecidas por Prometeu, foram dados aos homens por Zeus quando eles já haviam emergido na terra. Isso evidencia que, para Protágoras, a virtude cívica não é algo que o homem possui por natureza, pois é adquirida somente quando o homem passa a viver no mundo (KERFERD, 2003, p. 243). Além disso, no final da narrativa, Protágoras afirma ter mostrado as razões pelas quais os atenienses, com toda razão, permitem a todos a expressão de seus posicionamentos ante os assuntos relativos à virtude política: o poder da participação não advém da natureza, muito menos é espontâneo, mas, sim, produto da aprendizagem e da prática (Protágoras, 323c-d).

O ser humano nunca principia como um animal político, só ascendendo a esse patamar no decorrer da sua evolução social, quando transita do estado selvagem à condição civilizada. Consequentemente, sua virtude cívica nunca foi e não é uma quantidade fixa e permanente proveniente de um mundo transcendental, mas um padrão evolutivo de hábito, um conjunto de respostas às situações que se apresentam como valor comunitário (HAVELOCK, 1957, p. 170).

Para passarmos do relato antropológico de Protágoras sobre as origens da humanidade e a possibilidade de ensinar a virtude e adentrarmos nas peculiaridades da pedagogia retórica, devemos antes posicionar a prática linguística em relação às práticas social e política (JARRAT, 1998, p. 102). O primeiro aspecto a ser discutido concerne à declaração das pretensões profissionais de Protágoras, que dizia formar pessoas para ter discernimento, bom julgamento ou opinião correta, tanto em as- 
suntos privados quanto públicos, assim como para administrar com excelência seus negócios particulares e cívicos por meio do discurso e da ação (Protágoras, 318d).

Essas afirmações constituem a base teórica da "metodologia do julgamento social" ensinada por Protágoras, ou o processo de formar a decisão correta, a homonoia. A deliberação correta não é um ato único de "intuição ou vontade", mas um processo de raciocínio que gera conclusões práticas, pois, considerando que o campo em que se inserem é a gestão familiar e a administração cívica, os julgamentos que se formam nessa área são de natureza econômica, política e pragmática (HAVELOCK, 1957, p. 192). O processo de formação desses julgamentos, como também a sua reformulação, é, sobretudo, um processo retórico que envolve a realidade concreta.

Duas frases de Protágoras são esclarecedoras a esse respeito. A primeira diz que, sobre cada assunto, há sempre dois logoi (GARGARIN; WOODRUFF, 1997, p. 187); a segunda, que "cada coisa é para mim tal como ela me parece e é para você assim como lhe parece" (Theaetetus, 125a). Podemos compreender conjuntamente essas duas frases partindo do pressuposto de que, para Protágoras, nenhuma resposta ou opinião sobre determinado assunto pode ser julgada correta com o respaldo de algum sentido abstrato ou absoluto, mas apenas em relação às necessidades e aos interesses dos indivíduos envolvidos na experiência. Sua frase, no Teeteto (152b), é complementada com a observação de que o vento pode parecer frio a uma pessoa, e não frio a outra, pois o frio tem a ver com a experiência individual; o vento tem que ser "experienciado" antes, para que declarações sobre "qual é o caso" sejam possíveis e, sendo assim, que diferentes assuntos (logoi) sejam passíveis de ser verdadeiros (SCHIAPPA, 2003, p. 126). Enquanto Parmênides negava a realidade das qualidades contrárias e seu discípulo Platão as elevava ao mundo das formas, Protágoras considerava que as qualidades são diretamente percebidas ou experienciadas pelos seres humanos, portanto, elas "são" o que são, não em algum sentido abstrato, mas relativamente às pessoas envolvidas na experiência (SCHIAPPA, 2003, p. 127).

Uma vez que várias pessoas podem estar na mesma experiência ou situação problemática, pode ocorrer de surgirem vários logoi sobre a solução de determinado assunto e na elaboração da homonoia. Entretanto, podemos nos perguntar: como se dá esse processo de transição de julgamentos individuais para a constituição de uma identidade coletiva de pensamento? Adotando o pressuposto protagoreano de que todos têm capacidade para opinar a respeito dos assuntos da sociedade, temos que o julgamento feito por cada um dos indivíduos fornece base material para o surgimento de uma visão de mundo. Opera-se, então, uma seleção contínua de julgamentos individuais, de maneira que apenas os que resistirem ao teste da experiência serão validados e mantidos, permanecendo nessa condição somente en- 
quanto a comunidade os considerar adequados. Sendo assim, não se faz necessário um reino inacessível e transcendente, que garanta o valor dos conhecimentos que produzimos no mundo concreto. Tudo o que precisamos admitir são as diferenças de valoração e, portanto, a validade dos julgamentos feitos por diferentes pessoas (OEHLER, 2002, p. 210).

Ideias como verdade, beleza e bondade não são formas metafísicas que olham para o mundo como se fossem oriundas dos deuses; elas são fins experimentais que nós revisamos continuamente. São assim também as situações problemáticas que se apresentam a nós na realidade concreta, cuja solução depende de nossos julgamentos baseados na experiência, comunicada e compartilhada. A retórica surge desses pontos que obstruem nosso esforço para solucionar determinado problema ou julgar determinada situação, quando nossos hábitos são frustrados, nossos objetivos não são claros, e nossos métodos, opacos; quando somos instados a debater e deliberar sobre cada passo que damos na direção de uma realidade que está se processando no tempo (CRICK, 2010, p. 188).

Protágoras e os demais Sofistas arquitetaram a formação do indivíduo no espaço aberto à discussão oferecido pela democracia. Para que esse espaço público seja democraticamente útil, devemos educar os indivíduos, e essa educação vai além da discussão sobre livros ou construção de escolas; consiste sobretudo na tomada de consciência pelas pessoas de que a pólis é cada uma delas, e de que o destino da cidade depende do que elas pensam, fazem e decidem (CASTORIADIS, 2002, p. 312). Em suma, a educação consiste em participação na vida da comunidade, nos âmbitos político, social e cultural.

Apesar de não ser mencionado pelos doxógrafos como participante ativo da política de Atenas, como foi Protágoras, que teve grande influência sobre Péricles, Górgias impactou significativamente a cultura política da Grécia Antiga por formar os indivíduos por intermédio da retórica, visando às discussões democráticas que ocorriam nas assembleias e aos embates jurídicos que se davam nas cortes. $\mathrm{O}$ peso do conceito de homonoia e do poder exercido pelo lógos na vida dos indivíduos revela-se nos escritos de Górgias, quando tomamos para análise um de seus textos que chegaram até nós, o Elogio de Helena.

Nesse texto, Górgias inicia sua argumentação afirmando que compete a ele dizer o que é justo e refutar aqueles que detrataram Helena. O que Górgias pretende, ao dar uma lógica ao discurso, é libertar da culpa aquela que sofre por tão má reputação, desmascarando aqueles que a caluniam e mostrando a verdade, para fazer cessar a ignorância (DK 82B11, 2). Consistente com o esforço Sofístico em tomar um mito como objeto de análise, fazendo-o passível de crítica e alteração, Górgias torna a mítica Helena uma ré a ser defendida por seu discurso em um tri- 
bunal fictício (CRICK, 2015a, p. 81). O início do Elogio já mostra a intenção de seu autor: questionar uma homonoia, um consenso que se tinha a respeito de Helena e, assim, produzir uma nova identidade de pensamento, uma nova opinião a respeito dela (CASSIN, 1990, p. 78-79).

Górgias destaca, então, os possíveis motivos para o embarque de Helena para Troia. O primeiro motivo é que ela teria abandonado sua terra devido à influência dos deuses, do destino e pelos decretos da Necessidade. Caso tenha sido esse o motivo, não deveríamos culpar Helena, mas os deuses, uma vez que é impossível aos homens impedir um desejo divino (DK 82B11, 6). A segunda hipótese é que Helena poderia ter sido levada à força por Páris, sendo "não apenas ilegalmente forçada, mas também injustamente ultrajada". Caso tenha sido esse o motivo, devemos então culpar quem a raptou e ultrajou (DK 82B11, 7). Górgias apresenta uma terceira hipótese para justificar a fuga de Helena para Troia: ela poderia ter sido convencida pelo lógos, pelo discurso que enganou sua mente. Nesse caso, não é muito difícil livrá-la da acusação, pois o lógos é um "senhor soberano que com um corpo diminuto e quase imperceptível leva a cabo ações divinas" (DK 82B 11, 8). $\mathrm{O}$ discurso pode deter o medo, assim como afastar a dor; pode provocar a alegria e tornar mais intensa a paixão (DK 82B 11, 8). A palavra tem uma força mágica que fascina o espírito, convence-o e transforma-o por encantamento (DK 82B 11, 10). Por isso, temos todos os motivos para pensar que Helena pode ter sido seduzida contra sua vontade pelo discurso e arrastada por essa força poderosíssima a cometer o erro (DK 82B11, 12).

Um quarto motivo apresentado sugere a hipótese de Helena ter cometido o ato por causa de Eros, o amor. Ora, sendo o Amor um deus, como poderia Helena, simples mortal, rejeitá-lo ou afastá-lo? Se tratarmos o amor como uma doença humana ou um erro da inteligência, como podemos julgar como faltoso o ato de Helena, se é, antes de tudo, um infortúnio? (DK 82B11, 19). Sendo assim, Górgias (DK 82B11, 20-21) questiona: como podemos considerar justa a condenação de Helena, se ela fez o que fez por ter se apaixonado, por ter sido persuadida pelo discurso, arrastada pela violência ou forçada pelos deuses?

Um dos aspectos que o discurso de Górgias revela é a instabilidade do lógos. Ao mostrar que Helena pode ser inocente, toda uma tradição de poetas e de pessoas teria que mudar sua opinião a respeito dela, chegando a outro consenso sobre sua conduta. Isso mostra que, para Górgias, um consenso, assim como uma opinião, pode ser derrubado por outro no decorrer do tempo; nenhum consenso pode prevalecer para sempre (POULAKOS, 1995, p. 67). O texto de Górgias oferece uma "esplêndida demonstração" de como uma opinião amplamente aceita pode ser formada sem fundamento; nenhum argumento, consenso ou posição, não importa 
quão arraigado seja, pode dominar uma audiência para todo o sempre (CRICK, 2015a, p. 90). Ao operar com as polaridades do discurso, especialmente sua força e fraqueza, a retórica explora o caráter contraditório da linguagem, inventando reversões e violando suas regras; é por isso que, para Górgias, o discurso é um divertimento (POULAKOS, 1995, p. 71).

Considerando o objetivo de nossa discussão, devemos destacar que a argumentação de Górgias faz emergir um poder ainda mais importante do tirano lógos: o poder de construir uma unidade de pensamentos, sentimentos e opiniões. O lógos tem a capacidade de expandir nossa experiência para além de nossa percepção individual, produzindo um sentimento de comunidade, uma concordância, uma identidade de pensamento, um consenso.

Para entendermos a posição de Hípias a respeito do poder exercido pelo lógos na realidade concreta, veremos uma fala do filósofo de Elis apresentada no Prótagoras de Platão, conjugando-a com a análise de uma passagem no Hípias maior, obra em que Sócrates e o filósofo de Elis buscam a definição de belo. Em sua rápida aparição no diálogo Protágoras, Hípias afirma, dirigindo-se ao aglomerado de pessoas que ocupavam a casa de Cálias: "senhores aqui presentes, vejo-vos a todos como parentes, amigos íntimos e concidadãos por natureza, não por convenção", pois o semelhante se parece ao semelhante por natureza; a convenção, que "tiraniza a humanidade", nos constrange com frequência contra a natureza (337d-e).

Vemos que Hípias considera o nómos, a convenção e as leis, como algo que violenta a natureza das coisas, pois, ao formar uma opinião comum, que a sociedade considera correta e utiliza para orientar as relações humanas nesse ambiente, na maioria das vezes, as singularidades de determinados casos e experiências podem ser sobrepujadas ou até mesmo ignoradas para a formulação de uma identidade de pensamento. Em certos casos, a opinião comum não está em consonância com a realidade concreta, ficando em desacordo com a verdade, segundo Hípias.

Esse posicionamento de Hípias difere em grande parte do que pensam seus dois companheiros, Protágoras e, em especial, Górgias. Em seu Tratado sobre o não-Ser, o filósofo de Leontini é um dos primeiros a opor a opinião comum à ciência dos naturalistas, para quem a verdade de determinado julgamento ou enunciado é diretamente proporcional à sua coincidência com o real. Em seu Tratado sobre o não-Ser, Górgias afirma que a verdade ou aquilo que é verdadeiro não resulta do contato com um Ser uno, mas dos debates, das discussões e do exame crítico das posições apresentadas pelos discursos dos indivíduos. Em sua análise, Hípias considera tanto a visão dos naturalistas quanto o valor da simples opinião que se concretiza no consenso entre os homens. Ele não qualifica como científico qualquer julgamento que se diz verdadeiro, mas que não se possa submeter à verificação de 
sua concordância com a realidade concreta (DUPRÉEL, 1948). A opinião científica tem valor superior à opinião comum sobre a qual a homonoia é construída, mas o poder desses consensos obtidos via embate, deliberação e acordo entre opiniões comuns é de vital importância para a atuação dos homens em sociedade, para julgar e emitir uma avaliação a respeito das coisas no mundo, como veremos a seguir.

Sócrates e Hípias iniciam sua busca pela definição do belo em Hípias maior, partindo do pressuposto de que "a justiça, a sabedoria, etc. são algo", pois os justos, os sábios não seriam o que são se elas não fossem algo (Hipias maior, 287c). Eis que surge uma dificuldade: Sócrates questiona Hípias a respeito do que é o belo; o filósofo de Elis diz que, se alguém faz uma pergunta como essa, está interessado em descobrir algo além do que é belo. Sócrates corrige Hípias afirmando que o que se busca não é o que é belo, mas o que é o belo. O filósofo de Elis responde que não vê nenhuma diferença entre o que é belo e o que o belo é (Hípias maior, 287d).

Hípias percebe que Sócrates está procurando responder "que o belo é algo de tal tipo que jamais parecerá feio em parte alguma, a pessoa alguma" (Hípias maior, 291d). Essa percepção é atestada quando Sócrates diz que busca o "belo ele mesmo", por meio do qual tudo o que é agregado passa a ter sua propriedade, tudo passaria a ser belo, podendo ser uma pedra, um bastão, um homem ou um deus, todo ato e toda aquisição de conhecimento (Hípias maior, 292d).

Como se sabe, o diálogo termina em uma aporia, e os dois interlocutores não conseguem chegar a um consenso sobre o tema em pauta. A dificuldade para chegar a uma definição do que é o belo se dá, em grande parte, pela divergência entre o pensamento platônico e os princípios hipianos a respeito das formas, as ideias de justo, de belo, etc. Platão entende que a definição de tais ideias reside em um plano à parte do mundo concreto, em um espaço habitado pelo que é imutável, onde há sempre o mesmo para todos os objetos, pessoas, julgamentos, opiniões e conhecimentos predicados com tal adjetivo. Para Hípias, deve haver uma ideia geral do que seja o belo, ou seja, um ser, uma forma que reúna as verdadeiras qualidades do belo; qualidades que sejam reconhecidas por todos e em todo lugar. Entretanto, essa forma geral não se mantém estática e apartada da realidade concreta, como acreditavam os eleatas, especialmente Parmênides. Trata-se de uma forma múltipla que agrega elementos diversos, dependendo do espaço, do tempo, da percepção comum e da experiência de cada um, verbalizada por meio da linguagem. As formas, portanto, são inseparáveis das experiências dos seres particulares que são capazes de agir (DUPRÉEL, 1948).

Assim, operando por intermédio de experiências particulares e em face de situações que requerem um juízo acerca do que são as coisas, os homens podem, por meio do lógos, chegar a um consenso, uma opinião comum e correta do que seja $o$ 
belo. Apesar de essa opinião não ter respaldo científico, segundo Hípias, ela pode ser adotada como um "expediente utilitário" e, por isso, obter valor suficiente para dirigir uma ação eficaz (DUPRÉEL, 1948). A homonoia, então, constitui-se pela percepção de cada um, mediante compartilhamento, discussão e deliberação com outros indivíduos, podendo dirigir as ações no âmbito da sociedade; não tem o valor absoluto que possui a ciência, mas é suficiente para reger condutas (DUPRÉEL, 1948). Essa identidade de pensamento é construída pelos indivíduos agentes, levando em conta a natureza das coisas, o que for apropriado tanto às pessoas quanto às situações que a elas se apresentam, o ambiente, o tempo, a utilidade que tem para aqueles que são afetados pelo consenso obtido.

$\mathrm{Na}$ concepção hipiana, a tirania do lógos recebe uma nova face, de certa forma, um reflexo de seu homônimo; impõe sua vontade a cada indivíduo, levando-os a compartilhar, debater e deliberar sobre suas opiniões e experiências em direção aos consensos necessários à vida em sociedade. Tendo por instrumento a retórica ensinada por Hípias, o lógos, por intermédio da observação e do debate, deve minimizar a distância entre as identidades de pensamento formadas pela opinião comum e a natureza das coisas, tal como elas se apresentam no mundo concreto, com suas múltiplas formas e nuanças. Para Hípias, a realidade não é o reflexo de seres inertes, mas uma mistura de seres múltiplos que agem uns sobre os outros, constituindo um processo de influência mútua sem fim (DUPRÉEL, 1948).

Vistos em conjunto, os argumentos dos três Sofistas - Protágoras, Górgias e Hípias - possibilitam a reflexão de que, no terreno democrático, império do tirano lógos, o discurso não é apenas uma maneira de manter a convenção, dar ordens aos subordinados ou elogiar os governantes; o discurso é um meio pelo qual os cidadãos coordenam a ação voluntária por intermédio da persuasão nos momentos de julgamento (CRICK, 2015a, p. 66). A retórica Sofista entende que o mundo no qual reina o tirano lógos não é campo singular de discurso esperando para ser descoberto e distinguido de sua contraparte aparente, mas, sim, o espaço dos dissoi logoi, espaço humano de criações linguísticas que competem incessantemente entre si (POULAKOS, 1995, p. 188). Essa nova ordem, com o respaldo da democracia, evidencia uma estrutura de poder fundamentada menos em atos de votação particulares do que em pressupostos compartilhados, sendo os seres humanos a medida de todas as coisas; as melhores medidas são produzidas por meio do confronto e da reconciliação entre diversas perspectivas, e a retórica é a primeira entre as artes do lógos, pois é por seu intermédio que se constitui, se critica e se transforma o poder (CRICK, 2015a, p. 65). 


\section{Dewey e a retomada da Sofística}

O embate travado na Grécia Antiga entre Lógos e lógos influenciou a vida dos indivíduos e da sociedade, ecoando, bem mais tarde, no pensamento de John Dewey, cuja obra discute a importância da experiência na sociedade democrática. Em Democracia e educação, Dewey (1959a) retoma a discussão iniciada entre Platão e a primeira geração de Sofistas, para argumentar a respeito da noção de experiência. Tendo como ponto de partida a superação da dicotomia entre teoria e prática, Dewey ressalta que Platão e Aristóteles concordavam na identificação da experiência com interesses puramente práticos, especialmente aqueles ligados ao corpo e aos interesses materiais; a experiência sempre subentende falta, necessidade, desejo, nunca bastando a si mesma (1916/1959a, p. 288).

Segundo Dewey, essa dicotomia era proveniente do fato de a filosofia ateniense ter se iniciado com a crítica aos costumes e à tradição como padrões para 0 conhecimento e a conduta dos homens. A intensificação do comércio e das viagens, as colonizações, migrações e guerras ampliaram o horizonte intelectual da Grécia, ocasionando uma divergência considerável entre os costumes e as crenças dos gregos com os de outros povos (DEWEY, 1916/1959a, p. 289). Sendo os costumes e as explicações mitológicas incapazes de regular a vida da coletividade, os gregos buscaram nova fonte de autoridade para sua vida e suas crenças. Por entenderem que a experiência estava ligada aos costumes, recorreram a uma fonte mais elevada e abstrata, a razão (DEWEY, 1916/1959a, p. 303).

Os filósofos gregos procuraram mostrar a natureza instável e insuficiente da experiência, de modo a legitimar a supremacia da razão. É nesse contexto que devemos entender o Mito dos Metais de Platão, bem como a afirmação platônica de que os filósofos devem comandar os demais homens. Na concepção platônica, somente a razão pode assegurar o império da unidade, da ordem e da lei, e a escolha de um governo da racionalidade significa rejeitar a multiplicidade, a discórdia e a decadência da sociedade (DEWEY, 1916/1959a, p. 289). A experiência não oferece nada de bom à coletividade, uma vez que é desprovida da razão e tem um vínculo intrínseco com o que é mutável, incerto, múltiplo, o que varia com o tempo (DEWEY, 1916/1959a, p. 290).

Sendo assim, a filosofia grega dominante concebe que o material provindo da experiência é variável, inseguro e, por ser instável, anárquico. A experiência não é algo com que o homem possa contar para se orientar, pois ela varia de pessoa a pessoa, de dia a dia, de território a território. A conexão da experiência com o que é múltiplo, com as coisas particulares, também ocasiona conflitos entre os indiví- 
duos, entre seus atos e suas opiniões, fomentando crenças e posições contrárias (DEWEY, 1916/1959a, p. 291).

Dewey explica que, por não conseguirem lidar com a particularidade e a variabilidade da experiência e por preferirem se envolver exclusivamente com o abstrato, filósofos como Platão suprimiram a possibilidade de cada indivíduo ser um agente ativo nos assuntos concernentes à sociedade e conferiram a poucos aqueles que possuíam a tão apreciada faculdade racional - a direção dos demais e a escolha do que é melhor ao agrupamento. Dar à experiência, que é tão comum e passível de ocorrer com todos os seres humanos, a legitimidade para orientar as ações dos homens seria, antes de qualquer coisa, concordar implicitamente com a afirmação de que todos os indivíduos podem tomar parte nas discussões sobre o destino da pólis, que todos podem ter algo de bom a oferecer nesse debate. Platão não podia confiar na autoridade da tradição e dos costumes, mas também se via impossibilitado de atribuir valor positivo ao que se vincula à realidade concreta $\mathrm{e}$ mutável, império de um lógos inferior.

É nesse contexto que Dewey situa os Sofistas, que também sentiram a necessidade de criticar as instituições e os costumes existentes, mas adotando um novo ponto de vista: valorizaram a experiência como fonte de criação e de reavaliação dos consensos que norteavam a vida dos cidadãos na pólis democrática. Em vez de excluírem das discussões a massa dos indivíduos, os Sofistas optaram por valorizar o "livre jogo da inteligência", como bem atesta a admirável exaltação dos componentes da pólis feita por Péricles em sua Oração fúnebre (DEWEY, 1970, p. 17).

O conceito de experiência em Dewey segue um entendimento muito próximo do que foi elaborado por alguns Sofistas, especialmente Protágoras e Hípias. A primeira declaração que o aproxima de Protágoras consta no ensaio "The postulate of immediate empiricism", no qual afirma que "as coisas - qualquer coisa, todas as coisas, no uso ordinário ou não técnico do termo 'coisa' - são o que elas são experienciadas como"; desse modo, "se alguém deseja descrever alguma coisa verdadeiramente, tem por tarefa dizer o que é experienciado como sendo" (DEWEY, 1905/1977, p. 158).

Como afirma Crick (2010, p. 105), Dewey, assim como Protágoras, aceita a "realidade" dos objetos experimentados como experienciados de acordo com a situação em que a experiência ocorre e com os significados que o sujeito envolvido nessa relação lhes imputa. Condizente com as ideias hipianas, Dewey (1925/2008) considera que a experiência não pode ser vista como algo à parte da natureza. Para apreendermos o significado de algo, não podemos separar a experiência de tal coisa da situação na qual essa experiência ocorre (DEWEY, 1925/2008). Esse pressuposto deweyano enseja a ideia de que o conhecimento não pode ser apartado do 
contexto social, histórico, etc. em que se conhece, nem da forma como foi descoberto pela pessoa que conhece (CUNHA, 2012, p. 43). Dewey compreende a experiência não como algo relativo exclusivamente a eventos que ocorrem na mente de observadores passivos, e sim como um processo natural, que acontece sempre que seres humanos interagem ativamente com seu ambiente (SHOOK, 2002, p. 205).

Dewey não compartilha das concepções platônicas, que põem a experiência pretérita no campo do erro e do abandono e erguem o império da razão como legítimo regulador da vida social. Para Dewey, assim como para os Sofistas, devemos nos pautar nas sugestões advindas das experiências passadas, desenvolvê-las e amadurecê-las à luz das "necessidades e deficiências" do presente; devemos ver tais experiências como passíveis de reconstrução por meio da análise dos seus êxitos e fracassos, para que possam responder à situação presente para a qual são chamadas a contribuir. As experiências passadas não podem ser descartadas sem um trabalho prévio de seleção dos elementos úteis que irão servir à construção dos novos fins que a situação atual requer (DEWEY, 1920/1959b, p. 111).

Em conformidade com o pensamento Sofista, Dewey entende que o raciocínio, o exercício da razão por meio do qual se busca entender e elaborar ideias, fatos, atos e até mesmo juízos, é um tipo de "inteligência experimental" ligada ao mundo concreto (DEWEY, 1920/1959b, p. 111). É por intermédio dessa inteligência que os homens projetam os princípios, os planos e as ideias que guiarão suas ações. As hipóteses levantadas por intermédio da deliberação devem ser postas em prática, tendo os seus efeitos avaliados; o resultado dessa avaliação é que vai indicar se a hipótese deve ser rejeitada, corrigida ou ampliada, caso falhe ou tenha sucesso em proporcionar a orientação requerida pela experiência presente (DEWEY, 1920/1959b, p. 111).

Dewey e os Sofistas compreenderam que a inteligência não é algo inato, mas um constante processo formativo que exige observação das consequências dos atos de cada um e espírito aberto à aprendizagem e ao constante reajustamento (DEWEY, 1920/1959b, p. 112). Sendo assim, todos podem empregar a razão e o método experimental para tomar parte nas discussões que têm por meta regular e nortear a vida comum dos indivíduos, tal como Péricles havia proclamado, e Protágoras defendeu sabiamente em sua argumentação. Na medida em que os indivíduos têm a oportunidade plena de interagir, discutir e deliberar em público sobre os problemas que envolvem a sua comunidade, sua inteligência se desenvolve. A noção deweyana de inteligência contempla uma capacidade prática de lidar com os problemas efetivos que a sociedade real apresenta cotidianamente (POGREBINSCHI, 2004, p. 51). 
O crescimento individual, entendido como a capacidade de uma experiência cada vez mais rica e completa, não é algo que o ser humano possa exercitar sobre si mesmo, mas algo que depende da sociedade em que vive e que se amplia na mesma medida em que se amplia a complexidade do comportamento dos membros dessa comunidade (RORTY, 2006, p. 23). A experiência individual é fundamental para o desenvolvimento dos homens, mas apenas quando é compartilhada, formando valores e ideias comuns; é então que a experiência pode ser posta como o maior dos bens humanos (DEWEY, 1925/2008, p. 158). E esse compartilhamento só pode ser efetivado por intermédio da comunicação no interior de uma organização social em que as potencialidades individuais estejam livres de constrangimentos externos, sendo estimuladas, sustentadas e dirigidas (DEWEY, 1970, p. 39). Em suma, essa meta só pode ser cumprida em uma sociedade verdadeiramente democrática.

\section{O poder do lógos na sociedade democrática}

Seguindo a linha traçada por Protágoras, Dewey afirma que o ser humano, quando começou a falar, não tinha conscientemente em vista os objetos sociais, nem os princípios gramáticos e fonéticos pelos quais regularia seu esforço comunicativo mais tarde. A linguagem cresceu por meio de balbucios não inteligentes, por gestos e pela pressão das circunstâncias. Quando a linguagem foi chamada à existência, operou não para perpetuar as forças que a produziram, mas para modificá-las e redirecioná-las; sua criação foi ao encontro de antigas necessidades e abriu novas possibilidades; fez emergir uma demanda que surtiu efeito não apenas no discurso ou na fala individual, mas também na vida comum, na comunicação, em conselhos e instrução (DEWEY, 1922/2003, p. 58).

Uma ampliação importante do poder do lógos foi dada na Grécia Clássica devido à democratização, forma de associação que rompeu com as maneiras tradicionais de falar sobre o mundo. Dewey acredita que os Sofistas e sua formação no lógos, imersos no contexto democrático, foram "sintomas da mudança do regime do costume para o regime da análise e do pensamento reflexivo" (DEWEY, 1993, p. 32), o qual consubstanciava certa oposição entre os costumes sociais organizados em instituições e o processo de análise crítica inteligente (CRICK, 2010, p. 86).

Como vimos em Protágoras, os homens não conseguem sobreviver sozinhos, e, quando se agrupam, caso não tenham algo em comum, a existência fica ameaçada. Alinhando-se a essa consideração, a argumentação de Dewey (1970, p. 105) constata que, para determinado número de pessoas formar qualquer coisa que se possa chamar comunidade, uma associação qualquer, há que existir necessariamente valores apreciados em comum. Podemos estender essa afirmação dizendo 
que, para uma sociedade existir, devem haver opiniões comuns a respeito das ações a serem tomadas na resolução de conflitos, acordos e homonoia, a identidade de pensamento que permita a determinado agrupamento sobreviver às contradições e aos problemas que vão surgindo. Sem esses requisitos, qualquer grupo social, classe, povo ou até mesmo nação tende a se fragmentar.

Como já foi discutido neste trabalho, a homonoia, alicerce de toda e qualquer sociedade, tem como núcleo as opiniões dos indivíduos. O indivíduo julga e vê o mundo à sua volta, assim como a sociedade a que pertence; ele compartilha com o grupo não apenas os hábitos inerentes a essa associação, mas também a sua visão de mundo (MURPHEY, 1922/2003, p. XII). O homem vem ao mundo como indivíduo particular, mas sua sobrevivência depende das relações e associações que estabelece com outros indivíduos; é nesse processo que se põe o indivíduo em contato com a realidade externa, que se formam os costumes, as instituições e o próprio homem (DEWEY, 1922/2003, p. 45).

Assim como Protágoras, Dewey acredita que aquilo que chamamos de natureza humana não pode ser entendido como algo formado aprioristicamente. A escravidão, assim como a viu Aristóteles, e as distinções nativas da alma humana, como concebeu Platão, se interpretadas como formas arraigadas à natureza humana, fornecem elementos para justificar a crença de que algumas pessoas são dotadas do poder de planejar, comandar e supervisionar, enquanto as demais possuem apenas a capacidade de obedecer e executar (DEWEY, 1922/2003, p. 79). Para Dewey (1970, p. 111), quaisquer que sejam os elementos nativos que compõem a natureza humana, devemos observar que a cultura de um grupo em determinada época é formada sob a influência da distinção com outros grupos. O que Dewey queria dizer era que, se existe uma natureza humana, ela é essencialmente social, desenvolvida em um mundo formado pela herança cultural dos antigos, pelos fatos e acontecimentos do presente, pelas relações que os homens estabelecem entre si e pela experiência de cada indivíduo imerso nesse ambiente (CUNHA, 2001, p. 44).

Para Dewey, assim como para os Sofistas, a associação humana que pode proporcionar a melhor construção da natureza humana é a forma de vida democrática. Dewey considera que a democracia é um modo de vida orientado pela fé nas possibilidades dessa natureza, na medida em que ela existe em todo ser humano, sem distinção de raça, cor, gênero, nascimento e família, riqueza material ou cultural. Trata-se de uma fé que pode ser concretizada em forma de lei, mas apenas será efetiva quando colocada em vigor nas atitudes que os seres humanos adotam uns perante os outros, em todas as circunstâncias e relações da vida cotidiana (DEWEY, 1941/1988, p. 227). A fé de Dewey pode ser traduzida como uma crença 
na capacidade de todos os homens para o discernimento (judgment) e a ação inteligente (POGREBINSCHI, 2004, p. 51).

A democracia tem por tarefa primordial desenvolver e assegurar a libertação sempre crescente da natureza humana (DEWEY, 1970, p. 261); deve ser um meio de estimular o pensamento original e evocar a ação deliberadamente ajustada e antecipada para lidar com novas forças (DEWEY, 1922/2003, p. 49). De que modo a democracia realiza essa tarefa? Uma das peças essenciais para a consecução desse intento é a comunicação. A linguagem é uma função natural da associação humana, e suas consequências dão significado e significância a outros eventos, tanto de ordem física quanto humana (DEWEY, 1925/2008, p. 138). A linguagem é comunicação, não expressão de algo antecedente; é o estabelecimento de uma relação cooperativa na atividade, viabilizando parcerias entre os indivíduos e permitindo que a experiência de cada um seja modificada e regulada por essa mesma associação (DEWEY, 1925/2008, p. 142). A relação de nossos atos e experiências com os de outras pessoas em situações comuns revela a importância da comunicação como meio de direção social (DEWEY, 1916/1959a, p. 33). E a verdadeira ideia de direção social, para Dewey (1916/1959a, p. 39), consiste na formação de certa mentalidade comum, uma maneira de compreender coisas, eventos e atos que possibilitem a qualquer um participar eficazmente nas atividades associadas; eis a formação da homonoia.

Dewey ressalta que os indivíduos não constituem um agrupamento social apenas por trabalharem com fins comuns. Se aplicarmos essa ideia a uma máquina, cujas partes funcionam conjuntamente para a obtenção de um produto, vemos que, nesse caso, não há uma comunidade. Porém, se cada uma dessas partes tivesse conhecimento e domínio do fim comum e, mais ainda, interesse pela realização da meta proposta, regulando e ajustando sua atividade, estaríamos falando de uma comunidade. Para que isso ocorra, faz-se necessária a comunicação, pois cada parte precisa saber o que as outras almejam, precisa informar-se a respeito do andamento do trabalho e empenhar-se na formação de um consenso com as demais partes - afinal, é preciso que se disponha à comunicação (DEWEY, 1916/1959a, p. 5).

O que Dewey quer dizer é que a comunicação é a fabricação de algo comum, mas isso não implica impor à mente de cada indivíduo uma referência e um significado equivalente, e sim criar acordos comuns, consensos para ação (CRICK, 2010, p. 98); criar a homonoia necessária para a vida comunal. Essas identidades de pensamentos só são elaboradas quando a experiência individual é comunicada a outrem. Na medida em que nos associamos nesses empreendimentos comuns, as experiências particulares que os outros nos comunicam se fundem, de manei- 
ra imediata, com a experiência que resulta de nossa própria atuação (DEWEY, 1916/1959a, p. 205).

Mesmo que o fator primacial do desenvolvimento humano seja o coletivo, a mente individual tem papel relevante na operação construtiva. Grande parte das invenções e das melhorias nas artes tecnológica, militar e política tem sua gênese em "observação e engenhosidade de um inovador particular". Todas se dão na realidade concreta, com o propósito de melhorar a vida do grupo, mas a sua origem está na iniciativa de algum indivíduo que, em algum momento de atividade ímpar, desviou-se dos modelos e padrões costumeiros (DEWEY, 1922/2003, p. 165). A homonoia que dirige a vida associada e as condições sociais em que ela mesma acontece muda quando as iniciativas do inovador particular são levadas a cabo mediante o assentimento dos demais (DEWEY, 1922/2003, p. 170). Nesse contexto, comunicar não é o bastante: é preciso persuadir.

Para Dewey (1970, p. 215), o método democrático é o da persuasão por meio da discussão pública, o debate que acontece nos recintos legislativos, na imprensa, nas conversações particulares e nas assembleias públicas. Os conflitos que necessariamente emergem nesse contexto de debate, provenientes das diferentes opiniões e experiências dos diversos indivíduos participantes desse processo, só podem ser resolvidos pela aplicação dos métodos democráticos - consulta, persuasão, negociação, comunicação, inteligência cooperativa (DEWEY, 1970, p. 260).

De acordo com Crick (2010, p. 65), o problema do público democrático, para Dewey, é essencialmente um problema de comunicação, de necessidade de aperfeiçoamento dos métodos democráticos e das condições de debate, discussão e persuasão. $\mathrm{O}$ avanço dessas condições implica a existência de uma esfera pública que permita maior e mais efetiva participação de cada indivíduo e também o acesso aos métodos democráticos, que cada cidadão deve empregar para influenciar os pensamentos e comportamentos dos outros. É assim que a tirania do lógos se faz presente, e a retórica se mostra a arte mais eficaz para mover as audiências.

Apesar de Dewey dar o merecido valor ao lógos, entendido como raciocínio, comunicação, deliberação e debate, ele normalmente falha em reconhecer que os indivíduos que compõem a democracia carecem de ferramentas suficientes para a defesa de seus pontos de vista particulares, uma vez que bem poucos possuem formação em retórica (CRICK, 2010, p. 124). O público da democracia é formado por uma pluralidade de indivíduos que interagem mutuamente dentro de um ambiente compartilhado, e a democracia prospera não porque impõe brutalmente o desejo da maioria, mas porque cultiva e dá voz às minorias. É nesse cenário que se percebe que, além das funções persuasivas inerentes ao ensino retórico, os indivíduos necessitam desse instrumento para expressar e avançar os pontos de vista 
minoritários, de maneira a transformar a opinião pública em uma esfera pública igualitária (CRICK, 2010, p. 12).

Assim fez Górgias em seu Elogio, tendo o espaço e a oportunidade de persuadir os demais a concordarem com o seu ponto de vista sobre Helena, questionando a homonoia que até então dominava o imaginário de todos os gregos. A sociedade democrática necessita, portanto, acolher a formação no lógos, assumindo que, lado a lado com a persuasão, devem ser desenvolvidas a sensibilidade estética, a capacidade de discernimento e a razão como meios necessários para impelir a ação devida no tempo oportuno (kairós) e construir a homonoia que possa reger e estruturar a sociedade - ainda que provisoriamente.

Para Dewey, o meio social é educativo na medida em que possibilita ao indivíduo participar em atividades conjuntas, levando-o a contribuir com os demais, adquirindo a habilidade necessária para o desenvolvimento de atividades comuns e se deixando impregnar por certo "modo de sentir". É a educação que habilita os indivíduos a tomar parte nesse empreendimento coletivo, pois é a educação que cria nas pessoas a disposição para o compartilhamento e a plena participação na vida pública (DEWEY, 1916/1959a, p. 24).

Mesmo que se tenha destruído a ideia do monopólio do saber por poucos predestinados pela natureza, ainda vigora a ideia de que a educação adequada às massas deve ser pautada exclusivamente na formação prática, o que contraria frontalmente o desenvolvimento da "apreciação e da emancipação intelectual" (DEWEY, 1916/1959a, p. 282). Faz-se necessária uma transformação educacional radical, que produza a conciliação entre a formação intelectual e a formação prática; uma educação que desenvolva progressivamente as possibilidades presentes, tornando os indivíduos aptos para lidar com os problemas atuais e com as exigências futuras (DEWEY, 1916/1959a, p. 60).

Assim como Protágoras, Dewey (1920/1959b, p. 192) acredita que a natureza humana é passível de educação, mas a educação só é integral quando cada pessoa assume a responsabilidade pela formulação de ideias e programas de ação na vida social. A educação é muito mais do que a mera transferência de valores da comunidade para os educandos; a educação é participação política; a educação é peça fundamental para que o projeto democrático tenha chance de dar certo (CUNHA, 2001, p. 53). Para que se efetive o convite da democracia para participação política de todos, há que se formar os indivíduos na fonte da qual brota o poder do jogo político democrático, o lógos. Há que se ministrar uma educação retórica. 


\section{Considerações finais}

Por intermédio da exposição dos marcos discursivos dos autores analisados, esperamos ter mostrado que a tirania do lógos difere das tiranias tradicionais, ao impor a liberdade aos homens, fazendo com que saiam de suas casas e estabeleçam relações com outros indivíduos, a fim de que, juntos, possam criar o mundo no qual estão imersos. O tirano lógos mostra aos homens que a razão é a inteligência que articula os conhecimentos construídos em conjunto e aplica-os na elaboração de experiências mais ricas e emancipadoras, com o propósito de fazer progredir a vida humana. O tirano revela aos homens que existe um instrumento de atuação política e social, a retórica, que pode auxiliar na persuasão a respeito de como pensar, criando, consequentemente, a disposição para agir.

Apesar de Protágoras, Górgias e Hípias não utilizarem o termo retórica para discorrer sobre a educação no lógos, pois a palavra retórica foi cunhada tardiamente, e, apesar de Dewey a utilizar como sinônimo de propaganda, a formação proposta por todos eles abrange plenamente os componentes de uma educação retórica tal como a entendemos hoje. O terreno de atuação da retórica Sofista é o campo do possível, do verossímil, o qual se refere não a coisas determinadas e fixas, mas ao que tem a potencialidade de ser, mesmo que ainda não seja. Sendo assim, educar na retórica é ensinar os alunos a reconhecer que os limites do mundo podem ser ultrapassados; é criar neles a capacidade de enxergar a si mesmo e ao mundo não como algo dado, mas como algo que pode vir a ser (POULAKOS, 1995, p. 68). Não se trata de postular uma educação que prepare para o futuro, como o próprio Dewey critica, pois não há estímulo para o educando quando insistimos em deixá-lo pronto para situações que nem ele nem nós sabemos se irão mesmo existir um dia (DEWEY, 1916/1959a, p. 58).

Conjugada com a noção de possível, a formação retórica propõe uma educação kairótica, por meio da qual se desenvolva nos alunos a capacidade de analisar a situação presente e tentar, por meio do espírito inventivo e do método experimental, canalizar a seu favor as forças que se apresentam. A realidade se apresenta, então, como um campo de experimentação científica que fornece os elementos de experiência para criar e desenvolver novas formas, novas ideias e novas possibilidades de ação, visando alcançar o que é viável, por meio da deliberação consigo mesmo e com seus pares.

É por intermédio da educação que os hábitos e as virtudes são formados, e a cultura de determinada sociedade é transmitida de uma geração a outra (MURPHEY, 1922/2003, p. XXI). Se assumirmos como válida essa afirmação, temos que, por meio de uma educação retórica, podemos criar hábitos de deliberação, pen- 
samento crítico, debate, diálogo, invenção. A educação retórica tem o intuito de desenvolver a capacidade de analisar determinado assunto por diferentes perspectivas, a partir do embate entre diferentes posições, quando os indivíduos se põem a investigar e deliberar. Por meio do ensino das técnicas de persuasão, raciocínio, criação, estilo, consubstanciadas na formação retórica dos Sofistas, os alunos aprendem os elementos necessários para atuar como cidadãos ativos e conscientes, integrados a um modo de vida democrático, em que os rumos da coletividade são discutidos por todos. É nesse contexto que a deliberação tem papel essencial, uma vez que concerne à "natureza de juízos comuns" sobre o que é melhor ou pior fazer, quando várias linhas de ação possíveis se apresentam para o julgamento coletivo (DEWEY, 1922/2003, p. 179).

Crick ilustra a educação retórica com uma metáfora utilizada por Dewey. A sala de aula retórica deve propiciar os contextos deliberativos próprios de uma sociedade democrática. É como se nos tornássemos conscientes de intempéries e problemas, tais como pedras e tempestades, que podem surgir quando traçamos um itinerário de viagem em um barco a vela. Segundo Crick (2015b, p. 178), o educador é o responsável por trazer esses obstáculos para a sala de aula, partindo dos estudantes, utilizando seus argumentos, exemplos, crenças, hábitos e emoções. A deliberação é efetivada quando os vários "fatores em ação" se harmonizam, quando o mar se apresenta calmo e com ventos favoráveis para a navegação (DEWEY, 1922/2003, p. 181). A educação pode significar tanto a liberdade e a emancipação quanto a estagnação e a ausência de motivos para levantar âncora. Se não lutarmos para que a educação assuma a primeira feição, ela inevitavelmente assumirá a segunda.

\section{Notas}

1 Trabalho decorrente de pesquisa subsidiada pela Fundação de Amparo à Pesquisa do Estado de São Paulo (Fapesp).

2 Grafamos a palavra $\lambda o ́ \gamma o \varsigma$ com diferentes formatos, para especificar dois dos seus muitos significados no idioma grego.

3 Trata-se da palavra grega homonoia, traduzida pelos Sofistas por "identidade de pensamento", servindo para designar o "consenso entre os cidadãos", o acordo entre os homens (CASSIN, 1990, p. 196).

4 O texto de Górgias Tratado do não-Ser e a famosa frase de Protágoras: "o homem é a medida de todas as coisas" podem ser exemplos do teor dos questionamentos Sofistas aos princípios que regiam o pensamento grego no século $\mathrm{V}$ a. $\mathrm{C}$. 


\section{Referências}

CASSIN, Barbara. Ensaios sofísticos. Tradução de Ana Lúcia de Oliveira e Lúcia Cláudia Leão. São Paulo: Siciliano, 1990.

CASTORIADIS, Cornelius. As encruzilhadas do labirinto: os domínios do homem. Rio de Janeiro: Paz e Terra, 2002. v. II.

CHAMBLISS, Joseph James. The influence of Plato and Aristotle on John Dewey's philosophy. Lewinston: The Edwin Mellen, 1990.

CRICK, Nathan. Rhetoric and Dewey's experimental pedagogy. In: JACKSON, Brian; CLARK, Gregory (Org.). John Dewey rhetoric, and democratic practice: trained capacities. Columbia: University of South Carolina, 2004. p. 177-193.

. Democracy and rhetoric: John Dewey on the arts of becoming. Columbia: University of South Carolina, 2010. lina, 2015a.

Rhetoric and power: the drama of classical Greek. Columbia: University of South Caro-

Compor a vontade de poder: John Dewey sobre a educação retórica para uma democracia radical. Educação e Cultura Contemporânea, Rio de Janeiro, v. 12, n. 28, p. 164-183, 2015 b.

CUNHA, Ivan Ferreira. Rudolph Carnap e o Pragmatismo Americano: ferramentas para a filosofia da ciência. Tese (Doutorado em Filosofia) - Centro de Filosofia e Ciências Humanas, Programa de Pós-Graduação em Filosofia, Universidade Federal de Santa Catarina, Florianópolis, 2012.

CUNHA, Marcus Vinicius. John Dewey, a utopia democrática. Rio de Janeiro: DP\&A, 2001.

DEWEY, John. Democracia e educação: introdução à filosofia da educação. Tradução de Godofredo Rangel e Anísio Teixeira. 3. ed. São Paulo: Nacional, 1959a.

Reconstrução em filosofia. Tradução de António Pinto de Carvalho. 2. ed. São Paulo: Nacional, 1959b.

. Liberalismo, liberdade e cultura. Tradução de Anísio Teixeira. São Paulo: Companhia Editora Nacional, 1970.

. The postulate of immediate empiricism. The Middle Works of John Dewey, 1899-1924.

In: BOYDSTON, Jo Ann (Org.). The collected works of John Dewey, 1882-1953. Volume 3: 1905. Carbondale: Southern Illinois University, 1977. p. 158-167.

. Creative democracy - the task before us. The later works, 1925-1953. In: BOYDSTON, Jo Ann (Org.). The collected works of John Dewey, 1882-1953. Essays, Volume 14: 1941. Carbondale: Southern Illinois University, 1988. p. 224-230.

. Human nature and conduct: an introduction to Social Psychology. The Middle Works of John Dewey, 1899-1924. In: BOYDSTON, Jo Ann (Org.). The collected works of John Dewey, 1882-1953. Volume 14: 1922. Carbondale: Southern Illinois University, 2003. 
. Experience and nature. The later works, 1925-1953. In: BOYDSTON, Jo Ann (Org.). The collected works of John Dewey, 1882-1953. Volume 1: 1925. Carbondale: Southern Illinois University, 2008.

DEWEY, John. Philosophy and education in their historic relations. Transcribed from his lectures by Elsie Ridley Clapp and edited by J. J. Chambliss. Colorado: Westview Press, 1993.

DUPRÉEL, Eugène. Les Sophistes: Protagoras, Gorgias, Prodicus, Hippias. Neuchatel: Éditions du Griffon, 1948.

GARGARIN, Michael; WOODRUFF, Paul. Early greek political thought from Homero to the Sophists. Cambridge: Cambridge University, 1997.

GARRISON, Jim. Introdução à teoria do raciocínio prático de Dewey. Educação e Cultura Contemporânea, Rio de Janeiro, v. 3, n. 6, p. 13-43, 2006.

HAVELOCK, Eric A. The liberal temper in Greek politics. New Haven: Yale University, 1957.

JARRAT, Susan. Rereading the sophists: classical rhetoric refigured. Illinois: Southern Illinois University, 1998.

KERFERD, George Briscoe. O movimento sofista. Tradução de Margarida Oliva. São Paulo: Loyola, 2003.

MURPHEY, Murray G. Introduction. In: DEWEY, John. Human nature and conduct: an introduction to Social Psychology. The Middle Works of John Dewey, 1899-1924. In: BOYDSTON, Jo Ann (Org.). The collected works of John Dewey, 1882-1953. Volume 14: 1922. Carbondale: Southern Illinois University, 2003. p. IX-XX.

OEHLER, Klaus. Protagoras from the perspective of modern pragmatism. Transactions of the Charles Sanders Peirce Society, [s. 1.], v. XXXVIII, n. 1/2, Winter/Spring 2002.

PERELMAN, Chaim; OLBRECHTS-TYTECA, Lucie. Tratado da argumentação: a nova retórica. Tradução de Maria Ermantina Galvão. São Paulo: Martins Fontes, 1996.

PLATÃO. Theaetetus. In: . Complete works. Indiana: Hackett Plubishing Company, 1997. p. 157-234

A República (Da Justiça). Tradução de Edson Bini. São Paulo: Edipro, 2006.

. Protágoras (ou Sofistas). In: . Diálogos I. Tradução de Edson Bini. São Paulo: Edipro, 2007b. p. 249-320.

. Hípias maior (ou Do Belo). In: . Diálogos II. Tradução de Edson Bini. São Paulo: Edipro, 2016. p. 233-272.

POULAKOS, John. Sophistical rhetoric in Classical Greece. Columbia: University of South Carolina, 1995.

POGREBINSCHI, T. A democracia do homem comum: resgatando a teoria política de John Dewey. Revista de Sociologia e Política, Curitiba, n. 23, p. 45-43, nov. 2004.

REALE, Giovanni; ANTISERI, Dario. A sofística e o deslocamento do eixo da pesquisa filosófica do cosmo para o homem. In: (Org.). História da Filosofia: filosofia pagã antiga - v. I. Tradução de Ivo Storniolo. 3. ed. São Paulo: Paulus, 2007. p. 73-90. 
RORTY, Richard. Nietzsche, Sócrates e o pragmatismo. In: VIDAL, Vera; CASTRO, Suzana (Org.). A questão da verdade: da metafísica moderna ao pragmatismo. Rio de Janeiro: 7Letras, 2006. p. 19-26.

SCHIAPPA, Edward. Sophistic rhetoric: oasis or mirage? In: SCHIAPPA, Edward. Landmark essays on classical Greek rhetoric. California: Hermagoras, 1994. p. 5-18.

. Protagoras and logos: a study in Greek philosophy and rhetoric. 2. ed. Columbia: University of South Carolina, 2003.

SEXTO EMPÍRICO. Adversus Mathematicus. In: GÓRGIAS. Testemunhos e fragmentos. Tradução de Manuel Barbosa e Inês de Ornellas e Castro. Lisboa: Edições Colibri, 1993. p. 30-35.

SHOOK, John R. Os pioneiros do pragmatismo. Tradução de Fábio M. Said. Rio de Janeiro: DP\&A, 2002.

SILVA, Tatiane. A presença da filosofia platônica na Pedagogia do Estado Novo. Dissertação (Mestrado em Educação) - Programa de Pós-Graduação em Educação, Universidade de São Paulo, Ribeirão Preto, 2013.

TOULMIN, Stephen. Introduction. In: DEWEY, John. The quest for certainty. The later works, 1925-1953. In: BOYDSTON, Jo Ann (Org.). The collected works of John Dewey, 1882-1953. Volume 4: 1929. Carbondale: Southern Illinois University, 2008. p. VII-XXII.

TUCÍDIDES. História da Guerra do Peloponeso. Tradução de Mário da Gama Kury. 4. ed. Brasília: Editora Universidade de Brasília; São Paulo: Imprensa Oficial do Estado de São Paulo, 2001.

VALLE, Lilian. Castoriadis: uma filosofia para a educação. Educação e Sociedade, Campinas, v. 29, n. 103, p. 493-513, maio/ago. 2008. 